Review Article

\title{
Surgery in the COVID-19 pandemic
}

\author{
Satish Kumar*, Sanjay Pal, Suresh Kalyanasundar
}

Department of Surgery, Sharda Hospital, SMSR, Greater Noida, Uttar Pradesh, India

Received: 16 August 2020

Revised: 13 October 2020

Accepted: 14 October 2020

*Correspondence:

Dr. Satish Kumar,

E-mail: satish.kumar4@sharda.ac.in

Copyright: (C) the author(s), publisher and licensee Medip Academy. This is an open-access article distributed under the terms of the Creative Commons Attribution Non-Commercial License, which permits unrestricted non-commercial use, distribution, and reproduction in any medium, provided the original work is properly cited.

\begin{abstract}
The world is going through a difficult time with the COVID-19 pandemic for the last five months and has affected more than 200 countries. Wuhan in China was the first place and then this has spread all over the globe. The virus affects the respiratory tract predominantly leading to death more so in the elderly and those with comorbid conditions. All routine and planned surgical services had to be stopped in view of the very rapid spread of the virus compounded by the lack of a proper treatment. It has been nearly 90 days and surgical services need to restart. There are various protocols being practiced and we have also put up a protocol which is simple and wherein the disease has been triaged into three groups and accordingly treatment is executed. All surgical emergencies are treated considering them as COVID positive till proved by a negative test.
\end{abstract}

Keywords: COVID-19, Surgery, Pandemic

\section{INTRODUCTION}

Never did it cross one's mind that in a short span of time Christmas 2019 and Easter 2020 there will be a 360 degree change in the practice of medicine and surgery as the world is getting battered by the COVID-19 virus infection.

The COVID-19's ability to penetrate the humans and procreate inside the body starts the fight and the battle of survival of the fittest for human is just like a story from the science fiction. This has taken the healthcare workers community by surprise and we are still not been able to find a proper treatment; to further surprise the manifestation of the disease has been very variable and in a vast majority of cases the disease is asymptomatic and they are detected by testing the serum/throat for its presence (rapid antigen-antibody test). The ultimate weapon a vaccine to target the virus; seems to be a distant dream. The surgical fraternity has been trying to put up a protocol which can be both practical and possible to execute effectively.

\section{TIMING FOR REOPENING OF ELECTIVE SURGERY}

\section{Principle}

There should be a sustained reduction in the rate of new COVID-19 cases in the relevant geographic area for at least 14 days, and the facility shall have appropriate number of intensive care unit (ICU) and non-ICU beds, personal protective equipment $(\mathrm{PPE})$, oxygen $\left(\mathrm{O}_{2}\right)$ supply, ventilators and trained staff to treat all elective patients without resorting to a crisis of standard of care.

Elective surgery is designed to improve the quality of life and optimize clinical outcomes in patients who have a surgical management for non-urgent conditions. The Corona pandemic has forced physicians and health care systems to postpone such scheduled surgeries to ensure both the availability of resources and patient's/surgical staff's safety for those affected by COVID-19. 
The world surgical community has been evaluating the process of restarting elective surgical procedures world over with utmost care especially in elective surgical operations.

\section{TYPICALLY SURGICAL PATIENTS' TRIAGED FALL INTO THE FOLLOWING THREE GROUPS MENTIONED BELOW}

\section{Outpatient walk in}

Patients without co-morbidities and or well controlled morbidity, with a non-emergent surgical condition for routine planned surgery as an inpatient for a short stay: postponed for at least 04 weeks; a surgical procedure very short could be done and sent home. ${ }^{3}$

Patients have a surgical problem which needs to be addressed as a semi- emergency and most of them can be sent home after procedure with counselling and followed up in the outpatient's department (day care surgery).

\section{Surgical emergency needing early surgery}

Generally there is time to investigate and plan the procedure, however cannot wait for planned surgery or slot stabilization; start conservative management, COVID test done necessarily, operate and do minimum to tide over crisis; put patient in COVID isolation for further management.

\section{Acute surgical emergency with danger}

Acute surgical emergency with a danger to life if intervention is postponed beyond the time needed for resuscitation operate with all precautions and with proper consent from all health care workers (HCW); COVID test necessary.

If positive for COVID-19, treated completely and cured, group ' 1 ' should have a repeat test 48 hours before the day of surgery. If found negative we shall proceed for the operation with a proper consent detailing the increased risk of infection and other aspects of the disease.

If asymptomatic tested 7 days back found to be negative, group ' 2 ' patients are not yet ready for undertaking surgery, they were advised to return back after another 7 to 14 days with a fresh real-time polymerase chain reaction (RT-PCR) test for COVID-19 and re-evaluation.

If asymptomatic not tested, group ' 3 ' patients to be advised to get back after 2 to 4 weeks with two negative reports of COVID-19, 7 days apart. ${ }^{4}$

Group 3 were serious patient's often needing ICU care and will need surgical intervention as an emergency after resuscitation send COVID status and operate early considering the patient is COVID positive.
Laparoscopic approaches should be deferred till the pandemic settles down to a reasonable safe level as majority of these endoscopic procedures are aerosol disseminating procedures. As far as possible avoid using electrocautery as smoke can be a vehicle of transporting aerosol. $^{4,5}$

Laparoscopic procedures will need modification of operation theatres to negative pressure operation theatres with minimum 25 air changes cycle/hour and modification of instrumentation.

Guidelines issued by the local authorities Indian Council of Medical Research (ICMR), Ministry of health and family welfare (MOHFW) should be followed and any violation be punishable as per the disaster management act.

All known or suspected COVID-19-positive patients requiring surgical intervention must be treated as positive until proven otherwise in order to minimize infection spread.

All staff must be specifically trained to don, doff, and dispose of PPE including masks (level 2 or 3 filtering face piece (FFP) depending on the aerosol-generating risk level), eye protection, double non-sterile gloves, gowns, suites, caps, and socks (Table 1).

During the operation, all objects that come in contact with patients including blood, secretions, and excreta should be considered as potentially contaminated. In particular, medical staff in operating theater should avoid exposure to aerosols generated while using electrosurgical equipment.

There are many examples that viruses do survive in surgical smoke created by electrosurgical instruments., ${ }^{4,5}$ To reduce the hazards, surgical smoke should be minimized by suction device, and electrosurgical equipment should be used at the lowest effective power.

In suspected cases, laparoscopy should be avoided as pneumoperitoneum high-pressure trocar leaks enhance the risk of exposure to aerosol to operating theater staff.

Surgeons and nurses should avoid injuries such as stab wounds and needle stick injuries.

All PPE is only used in the isolated area and it is forbidden to leave the isolated area while wearing PPE.

In the operating theater, laminar air flow is used, and air supply should be closed after operation.

Hydrogen peroxide is used for fumigation. The operating theater should be cleaned and disinfected and highefficiency filter changed. Cleansing should be done using detergent and water followed by use of with 1000 parts per million (ppm) bleach solution for all hard surfaces in the 
operating theater. The disinfection time should be longer than $30 \mathrm{~min}$. The operation theater should be closed for at least 2 hours, and the next operation should be performed after laminar flow and ventilation being turned on. ${ }^{5}$

Table 1: Personal protection equipment.

\begin{tabular}{|ll|}
\hline S. no. & Personal protection equipment \\
\hline $\mathbf{1}$ & FFP2 facial mask FFP3 facial mask (in case of maneuvers at high risk of generating aerosolized particles) \\
\hline $\mathbf{2}$ & Disposable long sleeve waterproof coats, gowns, or Tyvek suits \\
\hline $\mathbf{3}$ & Disposable double pair of nitrile gloves \\
\hline $\mathbf{4}$ & Protective goggles or visors disposable head caps and disposable long shoe covers \\
\hline
\end{tabular}

Table 2: Sanitization sequence surface and electro medical sanitization sequence.

\begin{tabular}{|ll|}
\hline S. no. & Sanitization sequence surface and electro medical sanitization sequence \\
\hline $\mathbf{1}$ & Cleaning with chloro-derivate solution \\
\hline $\mathbf{2}$ & Rinsing and drying \\
\hline $\mathbf{3}$ & $\begin{array}{l}\text { Disinfecting with chloro-derivate solution in a concentration } \geq 0.1 \% \text { or } 1000 \mathrm{ppm} \text { time of contact must be } \\
\text { superior to } 1 \mathrm{~min}\end{array}$ \\
\hline
\end{tabular}

Table 3: Key aspects in COVID-19 surgical patient management.

\begin{tabular}{|c|c|}
\hline S. no. & Key aspects \\
\hline 1 & All suspected or infected patients must be managed with the maximum attention \\
\hline 2 & All personnel in contact with the patient must wear PPE \\
\hline 3 & Transfers must be protected \\
\hline 4 & Infected patients must be moved as little as possible through the hospital \\
\hline 5 & Transfer routes must be precisely planned and be as short as possible \\
\hline 6 & The COVID operating area should be in a dedicated and preferably separate area \\
\hline 7 & Transport personnel should be the same from transport origin to destination \\
\hline 8 & Once the patient has entered, the OR doors must be closed \\
\hline 9 & $\begin{array}{l}\text { Operators (i.e. surgeon, anesthetist, nurses, and technicians) should enter the OR in a timely manner to } \\
\text { minimize exposure to infected patients }\end{array}$ \\
\hline 10 & Personnel involved in the intervention should not leave the OR during the procedure \\
\hline 11 & High OR air exchange cycles are recommended ( $>25$ exchanges/hour) \\
\hline 12 & Clinical documentation must remain outside the OR \\
\hline 13 & $\begin{array}{l}\text { At the end of each intervention all disposable materials must be disposed of and all surfaces and } \\
\text { electrometrical devices accurately cleaned and disinfected }\end{array}$ \\
\hline 14 & $\begin{array}{l}\text { PPE must be removed and disposed of outside the OR in dedicated doffing areas ensuring the virus is not } \\
\text { transmitted to the healthcare worker }\end{array}$ \\
\hline 15 & OR and surrounding donning/doffing areas must be sanitized as soon as possible after each procedure \\
\hline 16 & After each procedure, all involved personnel, whenever possible, should shower \\
\hline 17 & Recovery phase after surgery must be done in OR, before transfer the ward/ICU \\
\hline
\end{tabular}

For high-risk patients who develop cough with fever after surgery, a chest computed tomography (CT) scan and RTPCR test should be performed during postoperative period.

\section{CONCLUSION}

All hospitals globally have closed the outpatient department for reasons to cater for the COVID-19 pandemic which has affected 215 countries already and the pandemic not shown signs of abating, in fact some countries feel that the pandemic is there to stay for a long and steps to accept and modify practices has come. These principles are essential for both patient care and safety of health care workers.
Elective surgery has been stopped all over the affected countries around 8 to 10 weeks back. Limited studies have been done and a general consensus has emerged that the adverse events are more and there is an increase in wound infections.

We are recommending an alternate approach in managing surgical emergencies and elective surgery in patients having COVID-19 active or having got the disease and recovering or recovered.

There is an urgent need for additional data to further identify risk factors for transmission during, before, and 
after surgery as well as to determine the optimal timing of surgery in these patients.

The take home message is routine elective surgical procedures to take back seat till further information and the disease gets into a plateau and a possible proper treatment and /or protocol will be available.

Consider all cases as COVID-19 positive till proved otherwise.

Funding: No funding sources

Conflict of interest: None declared

Ethical approval: Not required

\section{REFERENCES}

1. Huang C, Wang Y, Li X, Ren L, Zhao J, Hu Y, et al. Clinical features of patients infected with 2019novelcoronavirusinWuhan, China. Lancet. 2020;395(10223):497-506.

2. World Health Organization. Coronavirus disease 2019 (COVID-19) Situation Report. Available at: https://www.who.int/docs/default-source/ coronaviruses/situation-reports/20200318-sitrep-58covid-19.pdf? Sfvrsn=20876712_2. Accessed on 25 July 2020.

3. National Clinical Programme in Surgery. Information for surgeons regarding OPD triage during COVID-19 epidemic. Available at: https:// msurgery.ie/wp-content/uploads/2020/03/v3-NCPSguidance-tosurgeons-for-OPD-triage-duringCOVID-19.pdf. Accessed on 19 March 2020.

4. National Clinical Programme in Surgery. Information for surgeons regarding OPD triage during COVID-19 epidemic. Available at: https:// msurgery.ie/wp-content/uploads/2020/03/v3-NCPSguidance-tosurgeons-for-OPD-triage-duringCOVID-19.pdf. Accessed on 19 March 2020.

5. Ministry of health and family welfare. Government of India. Available at: https://mohfw.gov.in/. Accessed on 19 March 2020.
6. Tao KX, Zhang BX, Zhang P, Zhu P, Wang GB, Chen XP. General Surgery Branch of Hubei Medical Association, General Surgery Branch of Wuhan Medical Association. Recommendations for general surgery clinical practice in 2019 coronavirus disease situation. Zhonghua Wai Ke Za Zhi. 2020;58(3):1707.

7. Ciccolini F, Perrone G, Chiarugi M, Di Marzo F, Ansaloni L, Scandroglio I, et al. World J Emerg Surg. 2020;15:25.

8. National Clinical Programme in Surgery. Information for surgeons regarding OPD triage during COVID-19 epidemic. Available at: https:// msurgery.ie/wp-content/uploads/2020/03/v3-NCPSguidance-tosurgeons-for-OPD-triage-duringCOVID-19.pdf. Accessed on 19 March 2020.

9. Centers for Disease Control and Prevention. Interim guidance for healthcare facilities: preparing for community transmission of COVID-19 in the United States. Available at: https://www.cdc.gov/ coronavirus/ 2019-ncov/healthcare-facilities/guid ance-hcf.html. Accessed on: 19 February 2020.

10. Centers for Disease Control and Prevention. Interim infection prevention and control recommendations for patients with suspected or confirmed corona virus disease 2019 (COVID-19) in health care settings. Available at: https://www.cdc.gov/coronavirus/ 2019ncov/infectioncontrol/control-recommendation s.html. Accessed on 19 March 2020.

11. Joint Statement: Roadmap for Resuming Elective Surgery after COVID-19 Pandemic. American College of Surgeons American Society of Anesthesiologists Association of perioperative Registered Nurses American Hospital Association. Available at: https://www.asahq.org/aboutasa/newsroom/news-releases/2020/04/joint-stateme nt-on-elective-surgery-after-covid-19-pandemic. Accessed on 19 March 2020.

Cite this article as: Kumar S, Pal S, Kalyanasundar S. Surgery in the COVID-19 pandemic. Int Surg J 2020;7:3885-8. 